\title{
Nutritional Influences on Adrenal Chromaffin Cell Development: Comparison with Central Neurons
}

\author{
CHRISTOPHER LAU, FREDERIC J. SEIDLER, ANNIE M. CAMERON, HERNAN A. NAVARRO, \\ JOANNE M. BELL, JORGE BARTOLOME, AND THEORDORE A. SLOTKIN \\ Northrop Environmental Sciences, Research Triangle Park, NC 27711 [C.L., A.M.C.]; and Department of \\ Pharmacology, Duke University Medical Center, Durham, NC 27710 [F.J.S., H.A.N., J.M.B., J.B., T.A.S.]
}

\begin{abstract}
Neurotransmitter systems in the developing brain are generally protected from growth retardation associated with nutritional deprivation. To investigate if such protective mechanisms extend to similar tissues in the peripheral sympathetic system, maturation of the chromaffin cells of the adrenal medulla and development of their centrally derived splanchnic innervation were evaluated in rats whose nutritional status had been altered during the neonatal period by increasing (16-17 pups/ litter) or decreasing (five to six pups/litter) the litter size from the standard (11-12 pups/litter). Ontogeny of adrenal catecholamine stores and activities of catecholamine-biosynthetic enzymes tyrosine hydroxylase and phenylethanolamine $\mathrm{N}$-methyltransferase were monitored, along with activity of choline acetyltransferase, a marker enzyme for the preganglionic neurons innervating the chromaffin cells. Neonatal nutritional deprivation slowed body weight gain and retarded development of the chromaffin cells, as evidenced by subnormal catecholamine stores, tyrosine hydroxylase and phenylethanolamine $\mathrm{N}$-methyltransferase activities. The effects persisted despite the complete recovery of body wrights postweaning. The developmental alterations were not caused by overcrowding stress, as plasma corticosterone levels were not elevated in the large litter group. Neonatal nutritional enrichment promoted body weight gain but failed to enhance development of adres.al catecholamines; tyrosine hydroxylase and phenylethanolamine $\mathrm{N}$-methyltransferase activities were elevated only in the preweaning period. In contrast to effects on the chromaffin cells, altered neonatal nutritional status had only minor, transient effects on the development of the centrally derived cholinergic innervation of the adrenal and produced only small changes $(<\mathbf{1 0} \%)$ in brain tyrosine hydroxylase activity. These results suggest that, unlike central transmitter systems, maturation of chromaffin cells is adversely affected by neonatal nutritional deprivation; ontogenetic gains may already be close to optimum at normal nutritional status. (Pediatr Res 24: 583-587, 1988)
\end{abstract}

Abbreviation

ANOVA, analysis of variance

Received April 27, 1988; accepted July 6, 1988

Correspondence Dr. Christopher Lau, Mail Drop 67, U.S. Environmental Protection Agency, Research Triangle Park, NC 27711.

Supported by EPA 68-02-4450, EPA CR813769, and USPHS HD-09713. This paper has been reviewed by the Health Effects Laboratory, United States Environmental Protection Agency, and approved for publication. Mention of trade names or commercial products does not constitute endorsement or recommendation.
Growth and development of the newborn are influenced profoundly by nutritional status (1-3). Thus, in rats, manipulation of litter size produces marked differences in growth rates that are associated with changes in cell replication and differentiation, in structure and size of individual tissues, and in maturation of organ function. In contrast, development of the CNS is spared during neonatal nutritional deprivation and shows little or no enhancement of maturation during overnourishment (4). Recent studies confirm that selective intracellular and multicellular mechanisms participate in this process: maturational patterns of the ornithine decarboxylase/polyamine system, which regulates macromolecule synthesis during development, are maintained in brain regions at the expense of disruption of the same pathway in other organs (4). In fact, neural signals derived from the CNS actively participate in the suppression of peripheral development (5).

The sparing of general cell development that occurs in the CNS is paralleled by comparable protection of neurotransmission. Although shortfalls in neurotransmitter systems can be produced by undernutrition, they are of small magnitude and completely reversible by postweaning rehabilitation (6). The issue remains concerning if sparing is selective for the CNS or rather represents a phenomenon generalized to all neural tissues. The adrenal medulla, an integral component of the peripheral sympathetic nervous system, provides a convenient model with which to answer this question. Previous studies have shown that maturation of chromaffin cells and sympathoadrenal function occur primarily after birth in the rat and can be influenced by a variety of hormones and treatments (7-9). Accordingly, in the current study, we have contrasted the effects of nutritional enrichment or deprivation on development of chromaffin cells of the adrenal medulla with those on the centrally derived cholinergic neurons that provide their afferent innervation and with neurons in brain regions.

\section{MATERIALS AND METHODS}

Timed pregnant Sprague-Dawley rats (Zivic-Miller, Allison Park, PA) were housed individually in breeding cages and allowed food and water ad libitum. Immediately after birth, pups from all litters were pooled, randomized, and redistributed into three litter size groups: small litter (five to six pups), standard litter (10-11 pups), or large litter (16-17 pups). For each experiment, pups were chosen at random from several cages within each litter size group and groups were always sex-matched. The remaining rats were then randomized again within each group to maintain their respective litter sizes. All animals were weaned at 23 days of age.

At intervals of several days, rats were weighed and killed by decapitation, and adrenal glands were excised and homogenized 
(glass-to-glass) in $1 \mathrm{ml}$ of ice-cold $0.3 \mathrm{M}$ sucrose containing 25 $\mathrm{mM}$ Tris (pH 7.4) and $10 \mu \mathrm{M}$ iproniazid (irreversible monoamine oxidase inhibitor). A total of $100 \mu \mathrm{l}$ of the homogenate was withdrawn, deproteinized with $1.9 \mathrm{ml} 3.5 \%$ perchloric acid, centrifuged at $26,000 \times g$ for $10 \mathrm{~min}$, and the supernatant solution analyzed for norepinephrine and epinephrine by highperformance liquid chromatography (10). An additional $20 \mu \mathrm{l}$ of the homogenate were used for duplicate assays of choline acetyltransferase activity (9) using choline chloride as substrate and $\left[{ }^{14} \mathrm{C}\right]$ acetyl coenzyme $\mathrm{A}$ as acetyl donor. A $0.2-\mathrm{ml}$ aliquot of the homogenate was assayed in duplicate for phenylethanolamine $\mathrm{N}$-methyltransferase activity (7) using octopamine as substrate and $\left[{ }^{3} \mathrm{H}\right] \mathrm{S}$-adenosyl methionine as methyl donor. The rest of the homogenate was centrifuged at $26,000 \times g$ for $10 \mathrm{~min}$ to sediment the catecholamine-containing storage vesicles and the supernatant used for duplicate determination of tyrosine hydroxylase activity (11) using $0.1 \mathrm{mM}\left[{ }^{14} \mathrm{C}\right]$ tyrosine as substrate. Serum corticosterone levels were monitored by radioimmunoassay using $\left[{ }^{3} \mathrm{H}\right]$ corticosterone as tracer. Serum samples were extracted with ethylacetate, and free hormone was separated from the bound fraction by the dextran-coated charcoal technique as described by Abraham (12).

Three brain regions were examined: blunt cuts were made through the cerebellar peduncles, after which the cerebellum (including flocculi) was lifted from the underlying tissue; a cut was made caudal to the thalamus to separate cerebral cortex from midbrain plus brainstem. The regions were then weighed and homogenized in $4 \mathrm{vol}$ of sucrose-Tris. The two regions (midbrain plus brainstem and cerebral cortex) with significant amounts of tyrosine hydroxylase activity were then analyzed as described above, except that final concentrations of $0.7 \mathrm{mM}$ $\mathrm{CaCl}_{2}$ and $0.1 \%$ Triton $\mathrm{X}-100$ were added to optimize activity.

Statistics. Data are reported as means and SE. Because developmental data span order-of-magnitude differences (heterogeneity of variance), values were subjected to log-transformation before statistical evaluation by ANOVA. This manipulation gives equal weight to equivalent proportional changes (i.e. a $25 \%$ change at early ages bears the same weight in analysis as a $25 \%$ change at later ages). Accordingly, the data are presented as a percentage of control (standard litter size) values, which also gives equal weight to equal proportional changes; developmental profiles of the control rats are summarized in Table 1. Longitudinal comparisons were conducted by two-way ANOVA for adrenal data (factors of age and litter size) and by three-way ANOVA for brain regions (age, litter size, region). Individual differences among litter size groups were determined by Duncan's multiple range test. Significance was assessed at the levels $p<0.05$ and $<0.01$.

Materials. Acetyl coenzyme A [acetyl $\left.-1-{ }^{14} \mathrm{C}\right](53.5 \mathrm{mCi} /$ mmol), S-adenosyl-L-methionine [S-methyl- $\left.{ }^{3} \mathrm{H}\right](14.7 \mathrm{Ci} / \mathrm{mmol})$, L-tyrosine $\left[1-{ }^{14} \mathrm{C}\right](10 \mathrm{mCi} / \mathrm{mmol})$, and corticosterone $[1,2,6,7-$ $\left.{ }^{3} \mathrm{H}(\mathrm{N})\right](106 \mathrm{Ci} / \mathrm{mmol})$ were obtained from New England $\mathrm{Nu}-$ clear Corp. (Boston, MA); iproniazid phosphate, pyridoxal-5'phosphate, S-adenysyl-L-methionine chloride, choline chloride, sodium tetraphenylboron, physostigmine, acetyl coenzyme A, octopamine, $l$-norepinephrine $\mathrm{HCl}$, and $l$-epinephrine $\mathrm{HCl}$ from

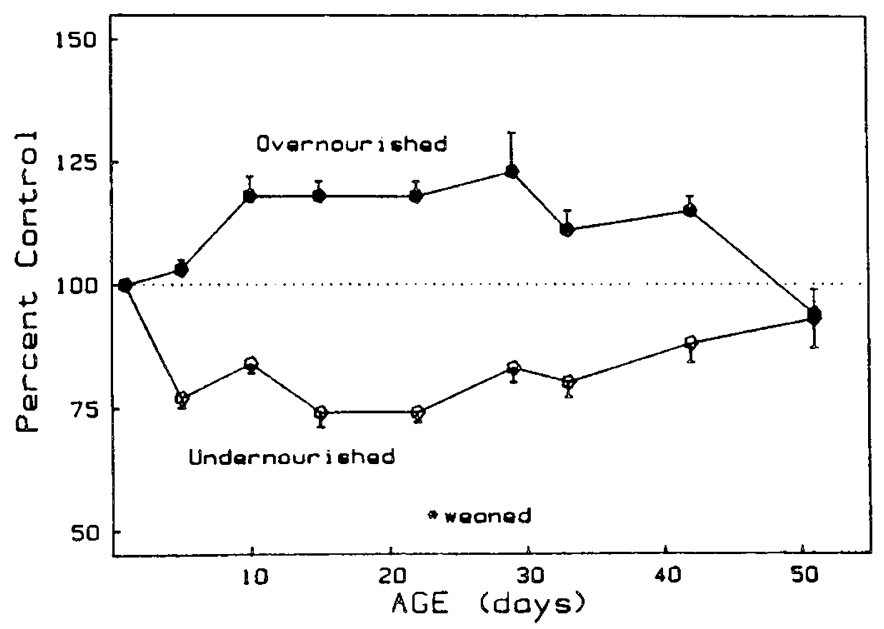

Fig. 1. Effects of litter size manipulation on body weights. Data represent mean \pm SE of 8-16 animals in each group at each age. Values from control rats (standard nutritional status) are in Table 1. Two-way ANOVA indicates a significant main effect of litter size $(p<0.01)$, as well as a litter size $\times$ age interaction $(p<0.01)$.

Table 1. Developmental characteristics of control rats (litter size of 10-11 pups)*

\begin{tabular}{|c|c|c|c|c|c|c|}
\hline $\begin{array}{l}\text { Age } \\
\text { (day) }\end{array}$ & $\begin{array}{c}\text { Body wt } \\
(\mathrm{g})\end{array}$ & $\begin{array}{c}\text { Adrenal } \\
\text { choline acetyltransferase } \\
\text { activity } \\
(\mathrm{nm} / \text { gland } / 30 \mathrm{~min})\end{array}$ & $\begin{array}{c}\text { Adrenal } \\
\text { tyrosine hydroxylase } \\
\text { activity } \\
(\mathrm{nm} / \text { gland/h) }\end{array}$ & $\begin{array}{c}\text { Adrenal } \\
\text { phenylethanolamine } \\
\text { N-methyltransferase } \\
\text { activity } \\
\text { (pm/gland/h) }\end{array}$ & $\begin{array}{c}\text { Adrenal } \\
\text { norepinephrine } \\
\text { (ng/gland) }\end{array}$ & $\begin{array}{c}\text { Adrenal } \\
\text { epinephrine } \\
\text { (ng/gland) }\end{array}$ \\
\hline 5 & $14.6 \pm 0.3$ & $0.51 \pm 0.02$ & $1.30 \pm 0.04$ & $24.2 \pm 2.8$ & $80 \pm 5$ & $569 \pm 21$ \\
\hline 10 & $23.1 \pm 0.4$ & $1.38 \pm 0.03$ & $1.41 \pm 0.11$ & $42.2 \pm 3.0$ & $193 \pm 12$ & $1276 \pm 67$ \\
\hline 15 & $35 \pm 1$ & $2.40 \pm 0.13$ & $1.52 \pm 0.09$ & $46.4 \pm 3.0$ & $462 \pm 31$ & $2215 \pm 152$ \\
\hline 22 & $55 \pm 2$ & $3.48 \pm 0.12$ & $2.27 \pm 0.11$ & $93.3 \pm 5.5$ & $1183 \pm 81$ & $3039 \pm 178$ \\
\hline 29 & $93 \pm 3$ & $3.99 \pm 0.24$ & $3.94 \pm 0.17$ & $219 \pm 15$ & $1754 \pm 117$ & $3450 \pm 412$ \\
\hline 33 & $128 \pm 8$ & $3.66 \pm 0.17$ & $5.32 \pm 0.42$ & $185 \pm 9$ & $1768 \pm 92$ & $4348 \pm 172$ \\
\hline 42 & $204 \pm 6$ & $6.44 \pm 0.41$ & $7.55 \pm 0.36$ & $284 \pm 37$ & $2375 \pm 135$ & $6436 \pm 304$ \\
\hline 51 & $256 \pm 15$ & & & $286 \pm 15$ & $2552 \pm 261$ & $7616 \pm 335$ \\
\hline
\end{tabular}

Brain region wt

\begin{tabular}{|c|c|c|c|c|c|}
\hline \multirow[b]{2}{*}{$\begin{array}{l}\text { Age } \\
\text { (day) }\end{array}$} & & \\
\hline & $\begin{array}{l}\text { Cerebral cortex } \\
(\mathrm{mg})\end{array}$ & $\begin{array}{c}\text { Midbrain }+ \text { brainstem } \\
(\mathrm{mg})\end{array}$ & $\begin{array}{l}\text { Cerebellum } \\
(\mathrm{mg})\end{array}$ & \multicolumn{2}{|c|}{$(\mathrm{nm} /$ region $/ \mathrm{h})$} \\
\hline 5 & $362 \pm 7$ & $163 \pm 4$ & $32 \pm 1$ & $2.4 \pm 0.2$ & $2.59 \pm 0.13$ \\
\hline 10 & $635 \pm 10$ & $259 \pm 6$ & $84 \pm 3$ & $6.6 \pm 0.3$ & $4.12 \pm 0.23$ \\
\hline 14 & $759 \pm 23$ & $300 \pm 9$ & $133 \pm 3$ & $10.8 \pm 0.6$ & $5.53 \pm 0.41$ \\
\hline 23 & $915 \pm 13$ & $360 \pm 9$ & $184 \pm 7$ & $17.0 \pm 0.9$ & $6.73 \pm 0.30$ \\
\hline 29 & $1010 \pm 13$ & $391 \pm 12$ & $222 \pm 6$ & $19.6 \pm 1.0$ & $6.79 \pm 0.32$ \\
\hline 33 & $1020 \pm 17$ & $431 \pm 16$ & $225 \pm 5$ & $27.2 \pm 1.5$ & $7.84 \pm 0.52$ \\
\hline 40 & $1070 \pm 20$ & $447 \pm 17$ & $238 \pm 4$ & $26.3 \pm 1.4$ & $6.43 \pm 0.38$ \\
\hline
\end{tabular}

* Data are expressed as means \pm SE of 8-16 animals. 
NOREP I NEPHR I NE

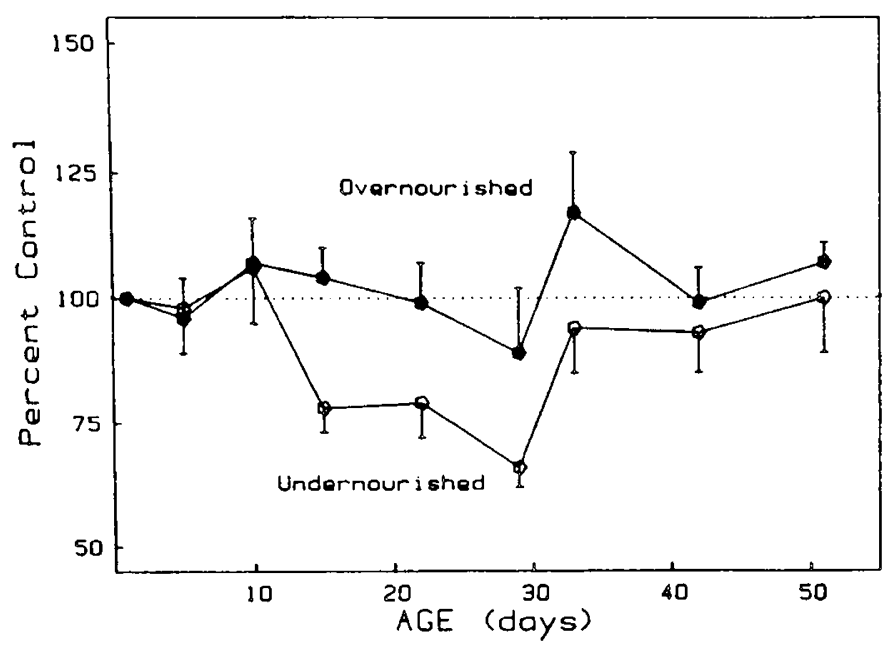

EP INEPHR INE

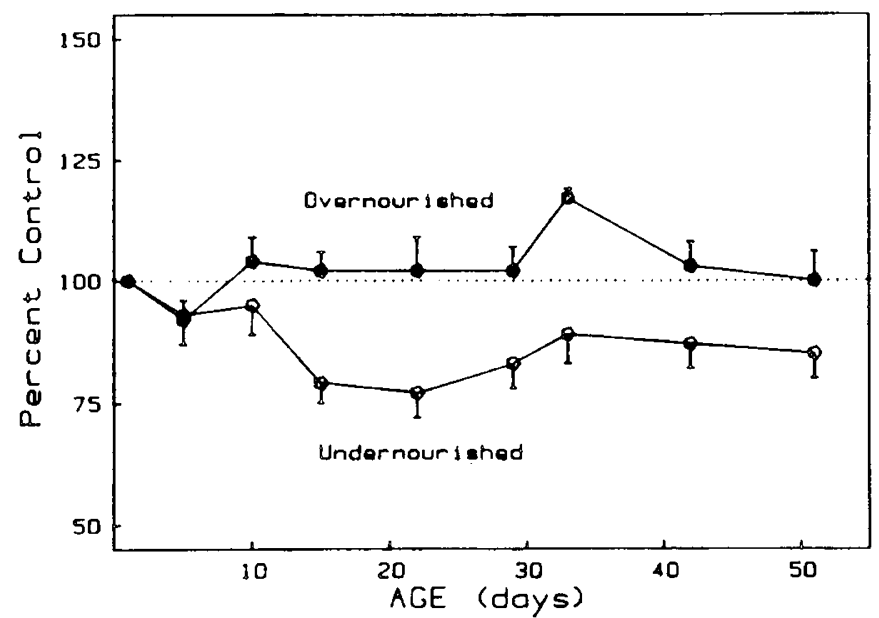

Fig. 2. Effects of litter size manipulation on adrenal norepinephrine and epinephrine. Data represent mean \pm SE of 8-16 animals in each group at each age. Values from control rats (standard nutritional status) are in Table 1. Two-way ANOVA indicates significant deficits in the undernourished rats $(p<0.01)$.

Sigma Chemical Co. (St. Louis, MO); and corticosterone antiserum from Radioassay System Laboratory (Carson, CA).

\section{RESULTS}

Nutritional manipulation produced highly significant shifts in body growth rates (Fig. 1). Compared to control animals (standard nutritional status), the undernourished neonates showed marked deficits that gradually disappeared after weaning. Conversely, overfeeding produced consistent enhancement of body weight over a similar time course.

Adrenomedullary development was also profoundly affected by nutritional status. In the undernourished rats, although nearly normal development of adrenal catecholamine levels was maintained for the first 10 days, both norepinephrine and epinephrine became subnormal by the second postnatal week (Fig. 2). Unlike the postweaning restoration of body weights, a catecholamine deficit remained (epinephrine) into young adulthood. To determine if there was a corresponding deficiency in the biosynthetic capabilities of the chromaffin cells, activities of tyrosine hydroxylase and phenylethanolamine $\mathrm{N}$-methyltransferase were evalu-
TYROSINE HYOROXYLASE ACTIVITY

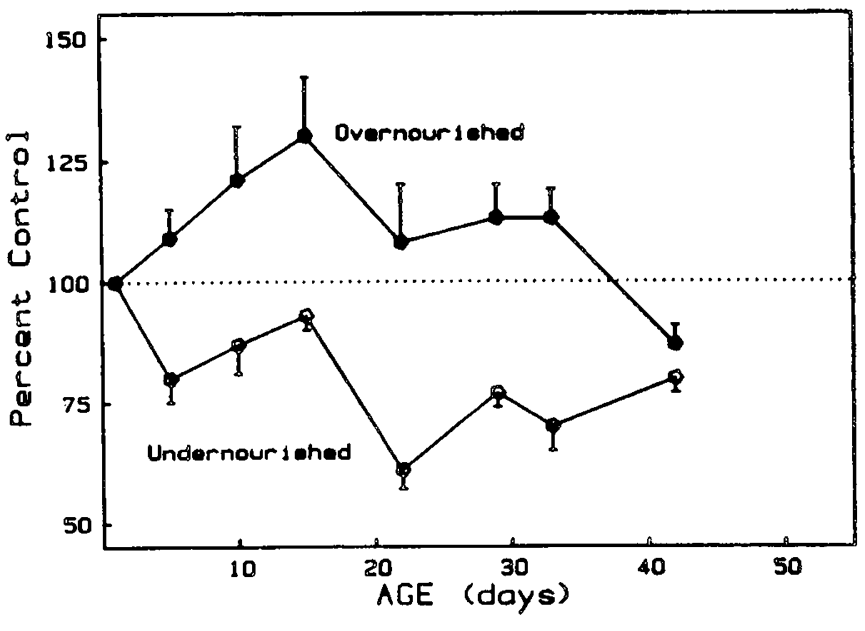

PHENYLETHANOLAMINE N-METHYLTRANSFERASE ACTIVITY

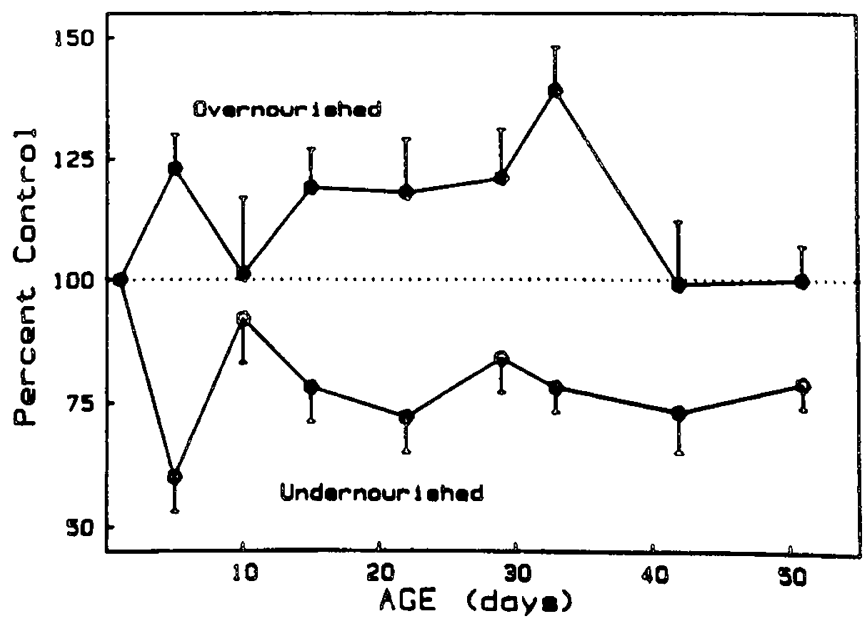

Fig. 3. Effects of litter size manipulation on adrenal tyrosine hydroxylase and phenylethanolamine $\mathrm{N}$-methyltransferase activities. Data represent mean \pm SE of eight animals in each group at each age. Values from control rats (standard nutritional status) are in Table 1. Two-way ANOVA indicates a significant main effect of litter size $(p<0.01)$ as well as a litter size $\times$ age interaction $(p<0.01)$ for tyrosine hydroxylase, and a significant main effect $(p<0.05)$ for phenylethanolamine $N$ methyltransferase.

ated. In the nutritionally deprived group, both enzymes were significantly suppressed throughout development (Fig. 3), and these deficiencies persisted despite the recovery of body weight.

In the overnourished group, no enhancement of catecholamine levels was obtained (Fig. 2); although significant elevations of both tyrosine hydroxylase and phenylethanolamine N-methyltransferase were seen, their activities returned to normal at young adulthood (Fig. 3).

To assess if altered neonatal nutritional status might also influence centrally derived neurons in the same pathway, we monitored adrenal choline acetyltransferase, a biochemical marker for the cholinergic nerve terminals innervating the chromaffin cells (Fig. 4). Undernutrition produced changes in activity of less than $15 \%$ which were no longer detectable by 5 wk of age.

Because changes in litter size (particularly overcrowding in the large litters) might produce stress, plasma corticosterone levels were measured at 8 and 16 days of age. As shown in Table 2, corticosterone in the large litter group did not differ from control values. In the overnourished rats, corticosterone was transiently 
elevated, an effect that is thought to represent enhanced maturation of the pituitary-adrenal axis associated with accelerated growth (13).

In contrast to the effects of litter size manipulation on adrenomedullary tyrosine hydroxylase activity, there was no main effect of litter size on the enzyme in the brain (Fig. 5). A

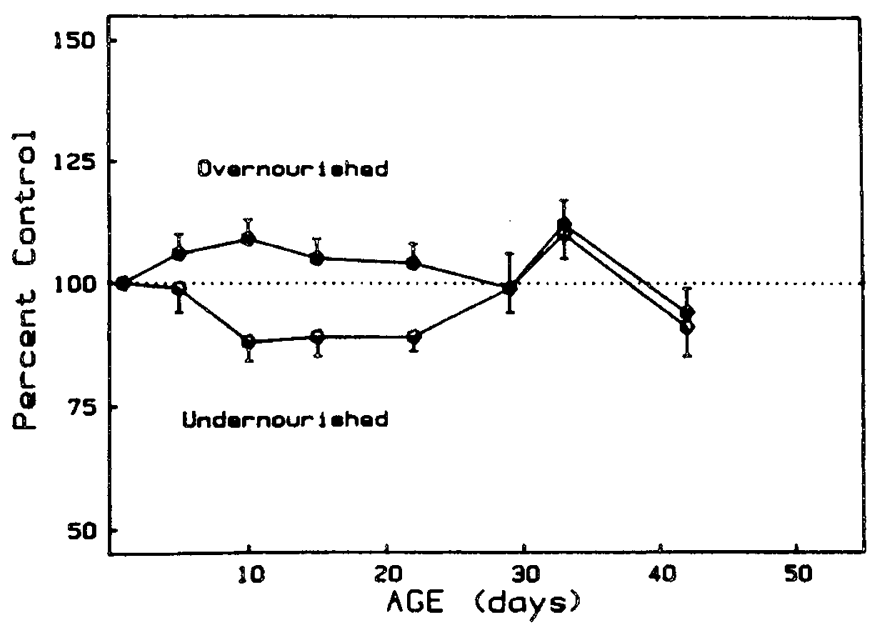

Fig. 4. Effects of litter size manipulation on adrenal choline acetyltransferase activity. Data represent mean \pm SE of 8-16 animals in each group at each age. Values from control rats (standard nutritional status) are in Table 1. Two-way ANOVA indicates significant depressions in the undernourished rats $(p<0.05)$. significant $(p<0.01)$ interaction of litter size $\times$ age $\times$ region across all three groups was present, indicative of transient changes in activity; further analysis showed that the difference was present only in the undernourished group (interaction of litter size $\times$ age $\times$ region, $p<0.05$ ). In one region (cerebral cortex), the effect was almost exclusively attributable to minor differences in tissue weight and in no case did alterations persist past the point at which body and tissue weights were restored to normal values. As expected, sparing of brain growth was prominent, with much smaller differences in brain region weight than in body weight.

\section{DISCUSSION}

Previous work has shown that the morphology and biochemical pattern of cell maturation is spared in the CNS of developing rats undergoing nutritional deprivation or enhancement (1-5). Consistent with these findings, we observed only small changes in brain region weight even in animals with substantially altered

Table 2. Plasma corticosterone levels*

\begin{tabular}{cccc}
\hline & \multicolumn{3}{c}{ Plasma corticosterone $(\mathrm{ng} / \mathrm{ml})$} \\
\cline { 2 - 4 } Age (day) & Overnourished & \multicolumn{1}{c}{ Control } & Undernourished \\
\hline 8 & $7.29 \pm 0.81 \dagger$ & $3.48 \pm 0.30$ & $4.09 \pm 0.56$ \\
16 & $35.0 \pm 5.1$ & $41.8 \pm 9.0$ & $36.1 \pm 5.6$ \\
\hline
\end{tabular}

* Data represent mean \pm SE of determinations from eight animals for each group.

$\dagger p<0.05$ versus control and undernourished groups.
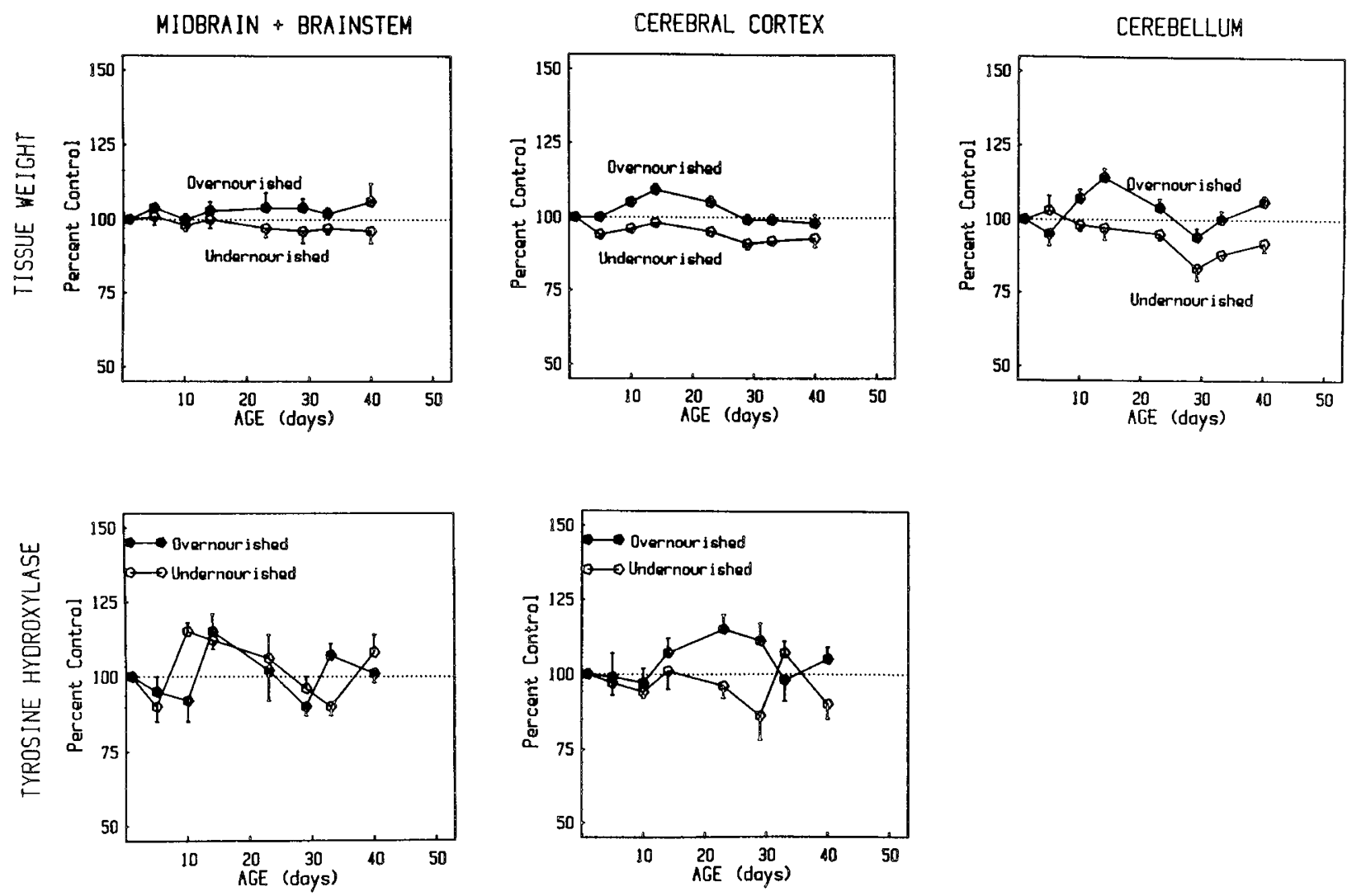

Fig. 5. Effects of litter size manipulation on brain region weights and on tyrosine hydroxylase activity. Data represent mean \pm SE of seven to eight animals in each group at each age. Values from control rats (standard nutritional status) are in Table 1. ANOVA indicates significant differences in region weights (main effect of litter size, $p<0.01$ ) which were age-dependent (interaction of litter size $\times$ age, $p<0.01$ ). For tyrosine hydroxylase activity across all three groups, ANOVA indicates an interaction of litter size $\times$ age $\times$ region $(p<0.01)$; subdivision of the groups indicates that the interaction was present only in the undernourished animals $(p<0.05)$. 
body weight. The extension of sparing to neurotransmitter development was evident in that the principal biosynthetic enzyme for catecholamines (tyrosine hydroxylase) was unaffected by overnutrition and only slightly and transiently influenced by undernutrition. The protective effect extended outside the brain to include peripheral neurons with their cell bodies lying within the CNS (splanchnic nerve): although shortfalls of choline acetyltransferase activity were noted in splanchnic projections to the adrenal, they were not permanent and were of far smaller magnitude than the pronounced lags of body weight gains seen in these animals.

However, the mechanisms protecting the CNS do not appear to extend to peripheral neural tissues even within the same pathway. In the underfed rats, adrenal catecholamine levels and biosynthetic capabilities were compromised, with enzymatic alterations persisting beyond the point at which body weights were restored. These results suggest that maturation of chromaffin cells is critically dependent on adequate nutritional support during early development. An important question is if these adrenomedullary deficits might be epiphenomena associated with glucocorticoid responses to overcrowding or other nonspecific stress. The ontogeny of both tyrosine hydroxylase and phenylethanolamine N-methyltransferase, as well as catecholamine levels themselves, are profoundly affected by corticosteroids $(8,14)$. However, the current results indicate no significant change in circulating corticosterone levels in the animals reared in large litters. The transient elevation of glucocorticoids seen in the nutritionally enhanced group is of some interest in that excessive steroid levels slow the course of cellular development in the CNS $(15,16)$; thus, this may represent one of the mechanisms that buffers the brain from accelerated maturation consequent to enhanced feeding.

In contrast to the perturbation caused by undernutrition, overnourishment had no significant effect on catecholamine levels in the chromaffin cells, although some elevations of tyrosine hydroxylase and phenylethanolamine $\mathrm{N}$-methyltransferase activities were noted. These results are consistent with previous findings that catecholamine storage capabilities, not biosynthetic enzymes, limit the rate at which amine levels increase during development (17). Additionally, the maturational rise in adrenal catecholamine turnover may keep step with increased biosynthesis $(17,18)$. In either case, it is apparent that development of catecholamine levels is already near optimal at normal nutritional status.

In conclusion, maturation of chromaffin cells of the sympathoadrenal pathway is adversely (and perhaps permanently) affected by nutritional deprivation during early development, whereas little effect is observed with comparable measures for centrally derived neurons innervating the adrenal medulla or in the brain. Ontogeny of catecholamine stores in the chromaffin cells appeared to be nearly optimal with normal nutritional status.

Acknowledgments. The authors thank Laure Antolick, Lisa Miller, and Kennedy Queen for their technical assistance.

\section{REFERENCES}

1. Brazier MA 1975 Growth and Development of the Brain: Nutritional Genetic and Environmental Factors. Vol. 1. Raven Press, New York.

2. Dodge PR, Prensky AL, Feigin RD 1975 Nutrition and the Developing Nervous System. CV Mosby Company, St. Louis, MO

3. Reinis S, Goldman JM 1980 The Development of the Brain: Biological and Functional Perspectives. Charles C Thomas, Springfield, IL

4. Bell JM, Whitmore WL, Queen KL, Orband-Miller L, Slotkin TA 1987 Biochemical determinants of growth sparing during neonatal nutritional deprivation or enhancement: ornithine decarboxylase, polyamines and macromolecules in brain regions and heart. Pediatr Res 22:599-604

5. Bell JM, Whitmore WL, Slotkin TA 1988 Neonatal nutritional deprivation or enhancement: the cardiac-sympathetic axis and its role in cardiac growth and stress responses. Pediatr Res 23:423-427

6. Wiggins RC, Fuller G, Enna SJ 1984 Undernutrition and the development of brain neurotransmitter systems. Life Sci 35:2085-2094

7. Lau C, Slotkin TA 1979 Accelerated development of rat sympathetic neurotransmission caused by neonatal triiodothyronine administration. J Pharmacol Exp Ther 208:485-490

8. Lau C, Slotkin TA 1981 Maturation of sympathetic neurotransmission in the rat heart. VII. Suppression of sympathetic responses by dexamethasone. J Pharmacol Exp Ther 216:6-11

9. Lau C, Ross LL, Whitmore WL, Slotkin TA 1987 Regulation of adrenal chromaffin cell development by the central monoaminergic system: Differential control of norepinephrine and epinephrine levels and secretory responses. Neuroscience 22:1067-1075

10. Felice LJ, Felice JD, Kissinger PT 1978 Determination of catecholamines in rat brain parts by reverse-phase ion-paired liquid chromatography. J Neurochem 31:1461-1465

11. Waymire JC, Bjur R, Weiner N 1971 Assay of tyrosine hydroxylase by coupled decarboxylation of dopa formed from $1-{ }^{14} \mathrm{C}-\mathrm{l}$-tyrosine. Anal Biochem 43:588-600

12. Abraham GE 1977 Clinical and biochemical analysis. In: Handbook of Radioimmunoassay, Vol 5. Marcel Dekker, New York, pp 591-656

13. Macho L, Hromadova M, Strbak V 1970 The adrenal function in rats with different growth rate. Endocrinol Exp 4:25-30

14. Sorimachi M 1977 Impaired maturation of presynaptic cholinergic nerve terminals in the superior cervical ganglia after administration of guanethidine and dexamethasone. Jap J Pharmacol 27:629-634

15. Anderson TR, Schanberg SM 1975 Effect of thyroxine and cortisol on brain ornithine decarboxylase and swimming behavior in developing rat. Biochem Pharmacol 24:495-501

16. Slotkin TA, Barnes G, Lau C, Seidler FJ, Trepanier P, Weigel SJ, Whitmore WL 1982 Development of polyamine and biogenic amine systems in brains and hearts of neonatal rats given dexamethasone: role of biochemical alterations in cellular maturation for producing deficits in ontogeny of neurotransmitter levels, uptake, storage and turnover. J Pharmacol Exp Ther 221:686-693

17. Slotkin TA 1986 Development of the sympathoadrenal axis. In: Gootman PM (ed) Developmental Neurobiology of the Autonomic Nervous System. Humana Press, New York, pp 69-96

18. Parvez S, Ismahan G, Parvez H 1980 Role of nutritional factors in the development of catecholamine synthesis and metabolism. In: Parvez $\mathrm{H}$, Parvez S (eds) Biogenic Amines in Development. Elsevier/North-Holland Biomedical Press, Amsterdam, pp 441-492 